\title{
ETHNOMETHODOLOGY AS AN EMIC GUIDE TO CULTURAL SYSTEMS: THE CASE OF THE INSECTS AND THE KAYAPO INDIANS OF AMAZONIA
}

DARRELI A. POSEY

\section{ABSTRACT}

This paper is an attempt to briefly summarize the taxonomic features of the folk entomological classification system of the Kayapó Indians of Central Brazil. The folk system shows a correlation with scientific taxonomies, especially at levels of Class, Order and Family. Several morphological continua os "sequences" are evident and within these are found additional sub-groupings called "complexes". Of particular interest is the sequence labeled "ñy", which is analogous to the scientific Orders of Isoptera and Hymenoptera. Patterns for these groupings reflect important social and cultural values and are indicative of the significance of social insects (bees, ants, wasps and termites) in the Kayapo belief system.

It is suggested that taxonomic systems are guides to culturally significant domains and point to underlying social and cultural patterns. These patterns are reified by mythology and oral tradition, being encoded as recurring symbolic forms with natural prototypes. Thus an ethnomethodology to determine folk classification systems offers an emic approach to the investigation of cultures and reveals the inter-relationships between cognitive systems, mythology, ceremony, and natural symbols.

\section{INTRODUCTION}

The Kayapó Indians are one of the major tribes remaining in Amazonia. Their well-earned reputation for belligerance and violence (cf. Wagley, 1977:31) kept them insulated from encroaching western society until 1938. In that year the first missionaries established permanent contact with the Gorotire Kayapó. The Gorotire represented only one of several schismatic groups, all of which had once been united in a powerful and populous ancestral village, Pyka-tô-ti (Posey, 1979b). Once the Gorotire had been "pacified" with Western trade items and medicines, other Kayapó ceased their warfare and established contact with Brazilian Indian Foundation (FUNAI) officials. The last group to be pacified was the Mekrãngoti Kayapó, who have now had less than twenty years of sporadic contact with the outside world (Verswijver, 1978).

Most of the data analyzed in this paper were collected in Gorotire, the largest of the northern Kayapó villages $\left(7^{\circ} 48^{\prime}, 54^{\circ} 46^{\prime} \mathrm{W}\right)$. Gorotire was the base camp for this 14-month project because of its accessibility and the presence of some bilingual (Kayapó and Portuguese) Indians.

Gorotire is one of seven northern Kayapó villages located in the reserva indigena Kayapó. The total Kayapó population is now over 2,500; the area of the reserva is approximately $1,900,000$ hectares. One of the aims of the Kayapó project was to determine the underlying logical basis of the Indian system for classifying natural phenomena. General biological classification was investigated, but since the investigator had special training and interests in entomology, insects became a focal concern. The goal of an ethnotaxonomic investigation is to define the cultural system using the cognitive categories utilized by people of the cultures under investigation. This emic approach requires a special methodology (or "ethnomethodology") designed 
to discover underlying patterns of logic and related cultural patterns. The following ethnomethodology evolved to generate the data analyzed in this paper.

\section{ETHNOMETHODOLOGY}

Research was at first limited to work with the 6 men and 3 women who spoke Portuguese. Although an attempt to learn and utilize Kayapó was made from the onset of the project, it was seven months before eliciting could be carried out in the indigenous language. The type of data gathered reflects these stages of the project.

One of the first tasks begun was to establish an insect collection. Daily field trips were taken for the sole purpose of collecting as many different insects as possible in categories the Indians loosely grouped together.

Four or five Indians accompanied the researcher on collecting forays that spanned the entire 14 month period. The result was a collection with a range of "relatives of insects" (consistently called "maja") expanded in what was assumed to be a reflection of native ideas of relatedness. The category included all insects, scorpions, ticks, centipedes, millipedes, crayfish, and pseudoscorpions. The category (maja) has a one-to-one correspondence with the scientific category of Phylum Arthropoda.

As the collection progressed, it became apparent that most organisms were grouped into very generalized categories. If there were no consistent sub-groupings (i.e., no named or un-named differentiations), the specimens in that group were boxed and sent to the Museu Paraense Emílio Goeldi for classification and storage in the Museu collections. ${ }^{1}$ If any evidence of subdivisions did exist, however, the specimens were retained in the village for further study.

In the village, informants were asked to (a) name each specimen, and (b) group those specimens that were the same (abenkôt) or similar (õmbiqua). In this manner, it was determined that covert (unnamed) groupings exist that correspond in a one-to-one fashion with the scientific Class of Arthropoda (see Table 1). Further sub-groupings were few, except for the covert category corresponding to the scientific Class Insecta. Eighteen (18) sub-classes ("forms") were found in this category (see Table 2).

Each specimen was numbered and each number was recorded in a master notebook. This notebook contained essential field data on the specimen, plus a sketch or field identification notation if possible. If appropriate, entries were also made regarding the cultural use of the insect or any peculiar circumstances under which the specimen was collected. (Often Indians would bring specimens to be examined because they thought them interesting, unusual or particularly significant).

Groupings of insects were tabulated initially for six men and three women; the maximal number of insects utilized in each of these sorting experiments was 635. Informants conducted the grouping activities on three different occasions, each time with actual insect specimens. The identification number of each specimen grouped was recorded for each category.

"Informant error" was treated as problematic since patterns in "error" were soon evident and eventually predictable. Based on these data, four (4) types of "forms" were identified (see Table 2).

(1) Focal forms, those consistently labeled and grouped in the same way and considered "typical" of the category. These forms are best illustrated as "fuzzy sets" (cf. Gardner, 1976; Kempton, 1978) with certain members being more focal and others being more peripheral.

1. A collection of nearly 6,000 insect specimens was deposited with the Museu Paraense "Emílio Goeldi" (Belém-Pará), under the supervision of Dr. Will'am L. Overal, head of the invertebrate zoology section. I am indebted to Dr. Overal for his limitless assistance in identification of both collections.

For discussions of the general importance of insects to indigenous peoples, see Posey, $1978,1980$. 
TABLE 1 - ARTHROPOD GROUPS

Arachnoidea

\begin{tabular}{|c|c|c|c|c|c|}
\hline (a) & Scorpionida & scorpion & makre & \multirow{2}{*}{ mak } & $1: 1$ \\
\hline (b) & Pseudoscorpionida & pseudoscorpion & makkyre & & $1: 1$ \\
\hline (c) & Phalangida & harvesters & hehpati & \multirow[t]{3}{*}{ heh } & $1: 1$ \\
\hline (d) & Araneae & spiders & heh & & $1: 1$ \\
\hline (e) & Acarina & mites/ticks & ten & & $1: 1$ \\
\hline \multicolumn{2}{|c|}{ Crustacea } & crayfish & $\mathrm{maj}$ & & $1: 1$ \\
\hline \multicolumn{2}{|c|}{ Diplopoda } & mil1ipede & morokrêt & & $1: 1$ \\
\hline \multicolumn{2}{|c|}{ Chilopoda } & centipede & kekek & & $1: 1$ \\
\hline \multicolumn{2}{|c|}{ Insecta } & insects & (covert & & $1: 1$ \\
\hline
\end{tabular}

(2) Transitional forms, those consistently "mislabeled" between two categories. These forms are viewed as being "like" two groups that are contiguous categories in a morphological sequence.

(3) Aberrant forms, those consistently labeled in one category, but given a special name because of unusual morphological characteristics.

(4) Collective forms, those consistently given the same name and grouped together, altlough informants point out members of a collective class may not "really" be the same. In the one collective form discussed in the paper, small flies (ngôire), members of the category were considered too small to have significant morphological features and were illustrated with small dots.

Utilizing tabulated responses and informant sorting responses, it was possible to link into a more generalized pattern eighteen (18) named groupings. These groupings seem to best coincide with the criteria of "basic object level" categories (cf. Dougherty, 1978; Rosch et al., 1976). Informant drawings and statements showed that the underlying patterns of these subordinate groupings were based on recognition of gross morphological features. (Figure 2 represents these basic groupings based on drawings done in Village Gorotire by Irã Kayapó in 1977).

\section{PATTERNS IN FOLK ENTOMOLOGICAL CLASSIFICATION}

For the Kayapó all things are divided into 4 categories: (1) things that move and grow, (2) things that grow but do not move, (3) things that neither move nor grow, and (4) man - a creature that is akin to all animals, yet unique and more powerful than most animals because of his social organization.

It is the covert (unnamed) category of "animal" with which this paper is particularly concerned. All animals are sub-divided into two named groups: those with "flesh" (called by the name "mry"), and those with "shells" and no flesh (called "maja"). ${ }^{2}$ This latter group, animals with shells and no flesh, coincides with the scientific phylum Arthropoda. Further folk subdivisions correlate with the five (5) scientific classes of Arthropoda (see Table 1).

2. It has been suggested by Cecil Brown and Terence Hayes (in private communication) that the category maja may be a generalized category describing all things that are of little economic utility. A review of my data tends to confirm this suggestion in most cases, but not in all (bees, for example, are of great economic importance but are still classified as maja). I retain my original definition of maja, but feel it important to point out the possiblity that maja is a more generalizable category, which would leave as "covert" the domain of animals with shells, but no flesh. 
TABLE 2 - LEVELS OF CORRESPONDENCE FOR INSECTS

B.O.L. categories* COMMON NAME CORRESPONDENCE LEVELS CORRELATION

Foca 1 Forms:

\begin{tabular}{|c|c|c|c|}
\hline (1) & màrà & beet $1 \mathrm{e}$ & Order (Coleoptera) \\
\hline (2) & ipoi & true bug & Order (Hemiptera) \\
\hline (3) & kapo & roach & (Family: Blattidae) \\
\hline (4) & krytkañet & $\begin{array}{l}\text { grasshopper, } \\
\text { cricket }\end{array}$ & Order (Orthoptera) \\
\hline (5) & wewe & $\begin{array}{l}\text { butterf } 1 y, \\
\text { moth }\end{array}$ & (Various Orders) \\
\hline (6) & kañeñet & dragonf $1 y$ & Order (Odonata) \\
\hline (7) & kokot & $\begin{array}{l}\text { leafhopper, } \\
\text { cicada }\end{array}$ & Order (Homoptera) \\
\hline $\begin{array}{l}(8) \\
(9)\end{array}$ & $\begin{array}{l}\text { pure } \\
\text { kôpre }\end{array}$ & f $1 y$ & Order (Diptera) \\
\hline (10) & rorot & termite & Order (Isoptera) \\
\hline (11) & mrum & ant & (Family: Formicidae) \\
\hline (12) & amuh & social wasp & (Family: Various) \\
\hline (13) & mehn & bee & (Family: Apidae) \\
\hline
\end{tabular}

Collective Forms:

(14) ngôire

minute (Various)

insects

Aberrant Forms:

(15) karêrê

earwig Order (Dermaptera)

Transitiona1 Forms:

(16) kapoti

(17) kungont

(18) mehnkamamuh giant roach, Order (Dictyoptera)

mantid

solitary

(Various)

bee \& wasp

honey wasp
(Genus: Brachygastera)
$1: 1$

$: 1$

$1: 1$

$+$

$1: 1$

$1: 1$

$1: 1$

$1: 1$

$1: 1$

$+$

$+$

t

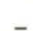

$t$

*B.O.L. - Basic Object Leve1 Categories

§Correlations stated in relation to correspondences at the scientific level of order ( $f$ indicates an over-differentiation; - is under-differentiation) 
Although the folk grouping that corresponds with "insects" is covert, there is a 1:1 relationship with the scientific class Insecta. There are four (4) morphological "sequences" within this grouping (see Figure 2). The term "morphological sequence" refers to a continuum of traits that unites a series of basic object level categories. The sequence may be an uninterrupted continuum with overlapping members between contiguous categories along the continuum; or there may be interruptions or gaps in the continuum. To bridge these gaps, named transitional forms may occur to produce intermediate categories (see Table 2).

Sequence 1: Let us look at Sequence 1 (see Figure 2) as an example. There is a continuum of gross morphological form from the OVATE "polar form" to the OBLONG "polar form" (see Figure 1). Within this sequence can be found two distinct complexes:

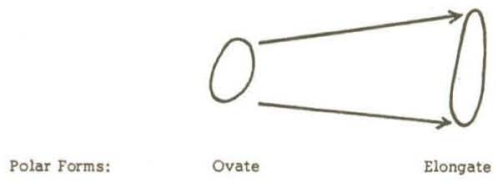

Fig. 1: Form sèquence.

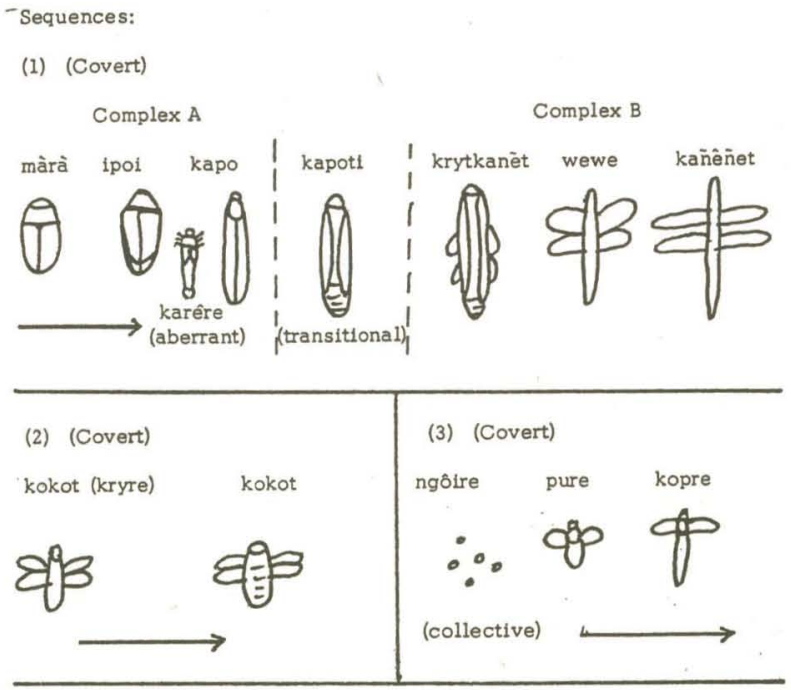

(4) "ñy" (social insects)

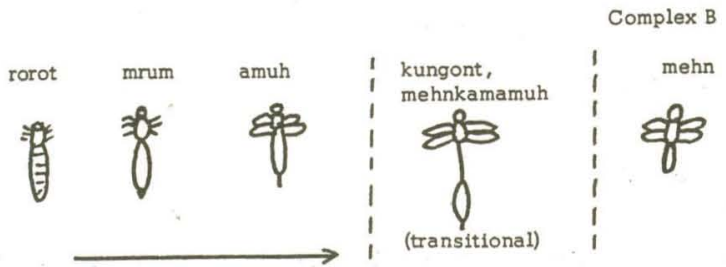

Fig. 2: Insect sequences and complexes (Based on drawings by Irã Kayapó). 
Complex $A$. This includes that part of the overall Sequence from beetles (màrà) to hemipterans (ipoi) to roaches (kapo). All forms in this complex have leathery outer wings or protective wing covers; their general form ranges from ovate to oblong. Considerable ambiguity occurs between these three (3) forms - that is, certain beetles are consistently classified as (màrà) and (ipoi), but never is there overlap between (màrà) and (kapo). Likewise many (ipoi) are classified as (màrà), but also as (kapo). No (kapo), therefore, are co-classified with (màrà). The earwig (karêre) is an aberrant form. It is consistently classified as a type of kapo, but is singled out because of its morphological distinctiveness (mainly because it has rudimentary wings and "pincers" on its abdomen) and given a special monomial label.

The overall sequence is interrupted with the transition from (kapo) to (krytkanet), i.e., from cockroaches to grasshoppers, although the morphological form continues toward elongation. This break is clearly due to the presence of large wings that become sufficiently conspicuous to define the perimeters of the animal's shape.

There is a transitional group, the (kapoti) or giant cockroaches, that bridges this gap. The large wings and elongated bodies of the group cause them to be co-classified with (kapo) and (kràtkañet). This transitional form has a distinctive name and coincides with the scientific Family Blattidae.

Complex B. The Sequence (Sequence 1) continues the second Complex (Complex B). In Complex B we have 3 overlapping genera: grasshoppers (krytkanet), butterflies (wewe), and dragonflies (kañeñet). The polar form is the dragonfly, whose form is distinctive because of its extremely elongated abdomen and 4 wings.

Sequence 2: This sequence consists of a single complex called (kokot). The continuum within the complex is one of smallness to largeness - the leafhoppers being considered the "children" of the larger cicadas. There is something of a form sequence from the slightly rounded leafhoppers to the ovate cicadas, but this seems insignificant to most informants.

Sequence 3: This sequence consists of a single complex of flies. It includes two (2) object level categories: (kôpre) tiny flies, and (pure) mosquitoes, biting flies, and pium. There is, as is expected, overlapping between contiguous categories and minor morphological form gradation from ngôire (tiny flies, which are drawn as small dots) and more slender mosquitoes.

Sequence 4: This sequence is composed of three (3) distinct object level categories in Complex A - termites (rorot), ants (mrum), and wasps (amuh). Complex B is composed of the single category, (mehn) honey bees. The break in the morphological sequence comes between wasps and bees. This may be attributable to the anomalous nature of bees, for they are the only shelled animal with major economic benefit. There are intermediate forms to bridge this functional gap. These intermediate forms are bees that make no honey and are solitary (kungont), and social wasps that do produce wax and honey (mehnkamamuh).

This is the only named Sequence, being called "ñy". This name refers to the social nature of these insects; the name is also used to label the immature forms (larvae and pupae) that the Indians say are carried about like children in the insects' "villages" (or urukwa). The "ñy" or social insects are seen to be in a special relationship to man because of their communal nature. All "ñy" colonies (urukwa) are thought to have a chief (ö-benadjwàra) and be organized into family units just like the Kayapó. They are known to have warriors and the sounds of their movements are likened to Kayapó movements and singing.

The Kayapó are aware that some "ñy" really live alone - that is, there are solitary forms. But they are as socially aberrant types that used to live in a "village", but for some reason now live alone. Solitary bees and wasps are like certain Kayapó who go off alone maybe for years on spirit 
guests, or are like true shamans, who are solitary by nature. These insects are associated with the manipulation of spirits and are important ingredients in the magical concoctions of shamans. In short, their anomalous nature in relation to other social Hymenoptera and Isoptera makes them important tools in the manipulation of natural powers by shamans. These aberrant forms are labeled with primary lexemes although they are consistently classified as a sub-group of the category (amuh) social wasps.

Except for Sequence 4 (termites, ants, bees and wasps), specific taxa are few for insects; sub-specifics are even fewer. Affixes denoting color, texture, size (or age), or some other general feature are frequently attached to the primary $\left(1^{\circ}\right)$ lexemic label of the generic category. An informant may choose any of a number of affixes to describe a specimen. Thus, (màrà-tyk-ti) means big, black beetle and the label may apply to any one of many beetles that are big and black. But the same beetle might also be called (màrà-krà-ti), big-headed beetle, if it were black and also had a big head. Occasionally a descriptive (or secondary lexeme) label may be reserved for a particular, limited set of insects. Within the beetle category is such an example, (màràtire) or dung beetles (Scarabaeidae). Each insect group (basic object level category) has a "father" (bam). The "father" is usually the largest member of the group. The "father" of the (màràtire) is the impressive rhinoceros beetle (Strategus, Scarabaeidae). It is called the (krã-kam-djware) and is also considered the "chief" (õ-benadjwàre) of all insects.

There are, however, only a few examples of this specific naming in Kayapó insect classification - except, within the Sequence (4) of "ñy", the social insects. There are 32 sub-groupings of (mrum) ants; 48 sub-groupings of wasps (amuh); and 57 sub-groupings of bees (mehn). These specific and sub-specific groups are generally labeled with secondary $\left(2^{\circ}\right)$ lexemes. But why does this specialized classification occur only within the Sequence "ñy"?

The importance of bees is evident: they are sources of honey and wax. ${ }^{3}$ But of what significance are wasps and ants? Already we know these animals are like man because they live in societies like the Kayapó: they have villages, chiefs, and warriors. But so do termites, yet there are only 4 sub-divisions of (rorot) termites. This is certainly not due to a paucity of termite types in the Kayapó area.

This anomalous situation leads the ethnographer into lines of inquiry regarding the Kayapó perception of qualities and characteristics of social insects. The hypothesis would predict that because the sub-categories of social insects are relatively differentiated, that further investigation into the nature of social insects ( $\tilde{n} y)$ would elicit significant cultural and social data.

Indeed, research following these emic indicators revealed that social insects are central to the Kayapó belief system. To understand the distinction between bees, wasps, ants, and termites, for example, one must understand one of the most significant of the Kayapó myths: the story of the ancient fight with the giant rhinoceros beetle, the krã-kam-djware.

In ancient times the Kayapó lived in the sky with other animals. The Kayapó were then like other animals and Indians could understand animal languages. But in these ancient days, the Kayapó were weak and did not live in villages or have societies. Indians were not more powerful than other animals and certain animals, especially the beetles (mara) under the leadership of their "chief", the kra-kam-kjware, waged war against men. In the ancient days, in the sky, the Kayapó learned to organize themselves into groups and live in villages like the " $\tilde{n} y$ " (wasps and ants). Then in a great battle in those ancient times, the valiant and fearless warrior of the Kayapó defeated the kra-kam-kjware. That defeat established man as a creature more powerful than other animals because of two things: (1) the power came from the social organization, and (2) the great strength and valor of the

3. The importance of bees in the Kayapó culture is discussed in Posey, 1980, $1981 \mathrm{~b}$. 
Indian warriors that had also come from the wasps. The Kayapó had learned the wasps' secrets by carefully observing the behavior of wasps and had learned of their "power" that could be gotten through their potent stings. The venom of the wasps had been the secret; the aggressive, fearless attacks of the wasps had been the model for Indian warriors.

Today, on regular occasions, the Kayapó commemorate the acquisition of these secrets and their victory over the kra-kam-kjware. They are constantly searching for the nest of the most powerful and aggressive wasp, the amuhdja-ken (Polistes testaceicolor). When a nest is found that is sufficiently large (usually 1.5 meters long, 0.5 meters in diameter), scaffolding is erected (by night when the wasps are inactive) to prepare for a re-enactment of the ancient event. 4

In the numbing cold of a grey pre-dawn haze, the entire village goes solemnly to the site. The warriors dance at the foot of the scaffolding and sing of the secret strength they received from the wasps to defeat the giant beetle. The women wail ceremonially in high-pitched, emotional gasps as the warriors, two-by-two, ascend the platform to strike with their bare hands the massive hive. Over and over again they strike the hive to receive the stings of the wasps - until they are semi-conscious from the venomous pain.

This ceremony is one of the most important to the Kayapó. It is a re-affirmation of their humanity, a statement of their place in the universe, and a communion with the past. Time and space collapse to provide the unity of being - the continuity of life, history, identity and knowledge.

The wasp's nest itself is a symbolic statement of this unity. Its three-dimensional shape illustrates the relationships between the polar forms of the classification morphology - the ovate and elongate forms (See Figure 1). A cross-sectional view - or view from above or below - shows the circular form; a lateral view shows the elongate form. The nest is a graphic study of the relationship between these shapes.

Even more importantly, the general structure of the hive itself serves as a model of the universe. The hive is divided into parallel "plates" that seem to float just like the layers of the universe. The Kayapó say that today they live on one of the middle plates. But in ancient days, they believe they lived on another plate above the sky. Some Kayapó still live on an upper plate, the tribal elders say, and their campfires are the stars in the sky.

And below? From lower plates came the "worthless men" (non-Kayapó) (kuben-kakrit). Many kuben-kakrit still live below, though most have already ascended to "this earth layer" through a termite mound.

Termites are in alliance with "worthless people" and termites themselves are worthless. They are weak (rêrêkrê) and cowardly (wajobôre), and, although they appear to live like Indians and social insects, they are neither brave (akrê) nor strong (tytx) like wasps or Kayapó warriors. No Indian would, therefore, find value in studying termites (rôrôt). They are sub-grouped only according to whether they are white, red, or black - the skin colors of non-Kayapó "worthless people." (A fourth sub-grouping labels the termite that lives in the mound through which came the kuben kakrit).

And what of ants? They are more like men than even wasps because they walk and hunt on the ground. The Kayapó believe that ants too have special powers because of their stings. But the power received from ants is more useful on man's hunting ally - the dog. Ants are used in many concoctions to make a hunting dog unafraid to keep his nose to the ground and to make him aggressive. Some ants are seen as excellent hunters, so often man and dog are adorned for the hunt with the sacred red urucu paint mixed with ant parts. To be good hunters, therefore, the Kayapó must know ants, just as they must know wasps to be brave and fearless warriors.

4. For more complete description of the wasp ceremony, see Posey, 1979c. 
This analysis indicates that insects are encoded at a "basic object level" (BOL), the predominating characteristic being gross morphology (shape) that grades from an ovate polar form to an elongated polar form. Between these two polar forms lie named categories of insects that form contiguous or overlapping sets called Sequences. The continuum of each Sequence may be interrupted by "gaps" due to natural discontinuities in nature. These "gaps" are reflected by Transitional and Aberrant forms.

Within the Kayapó classification system for insects there are four Sequences (continua), of which only one is given lexical recognition (the others are "covert" or unnamed categories). The named Sequence ( $\tilde{n} y)$, composed of social insects, is in sharp contrast to other meagerly differentiated animal categories because of the highly elaborated domains for wasps, bees and ants.

Semantic domains that are highly elaborated indicate categories of cultural importance; the degree of differentiation within a domain is a measure of cultural significance. Thus, based on these assumptions, it was predicted that investigation along these emic lines of inquiry would reveal important characteristics and qualities of the Kayapó belief system. The elaboration of the Basic Object Level categories within the Sequence $\tilde{n} y$ were in fact shown to be directly related to Kayapó beliefs about the origin of society, composition of the world, and the unifying concept of universe. Wasps (amuh), for example, are seen as models for social organization and are "fought" in an elaborate ceremony to reify their significance to the Kayapó culture. The nest of a Polistes wasp is a recognized visible model of the universe and a symbolic representation of social organization and political relations.

The relationship between polar morphological forms of the Kayapó system and mythology also suggests very interesting avenues for theoretical investigations. It is suggested that the shape of the wasp nest and the morphological model produced by the continuua of shapes that form taxonomic Sequences are manifestations of the same underlying cognitive system. That is, the hypothetical 3-dimensional relationship between polar forms is a replication of the natural 3-dimensional form of the wasp nest.

It is hypothesized that discernable patterns in the folk classification system represent underlying cognitive structures, which are given social significance through mythology and cultural manifestations in natural forms. Additional research must be carried out and the hypothesis tested to determine if similar relationships exist in other folk cultures. If such patterns continue to emerge, an important theoretical bridge between cognitive and taxonomic structures and mythological systems will have been established.

At the very least, the Kayapó data indicate the potential of ethnoscience for the study of cultural systems and the direct relationships that can exist between semantic domains and social reality as reflected in mythology and ceremony. Ethnomethodology can reveal significant semantic domains that are not only indices to cultural systems, but also emic guides for additional investigation. This offers anthropologists and other social scientists a methodology for initial inquiry as well as culturally significant indicators for the design of subsequent research.

\section{ACKNOWLEDGMENTS}

Funding for this project was made by the Wenner-Gren Foundation for Anthropological Research. Brazilian sponsors of the project were the Conselho Nacional de Pesquisas ( $\mathrm{CNPq}$ ), the Instituto Nacional de Pesquisas da Amazônia (INPA), the Museu Paraense 'Emílio Goeldi', and the Fundação Nacional do Indio (FUNAI). I am most grateful to the Institutions for their support.

An earlier English version of this paper, entitled "Wasps, Warriors, and Fearless Men: Ethnoentomology of the Gorotire Kayapó of Central Brazil" can be found in The Journal of Ethnobiology (Posey: 1981). 


\section{REFERENCES}

Bamberger, J., 1967. Environment and cultural classification: A study of the northern Cayapó. PhD Dissertation, Department of Anthropology, Harvard University.

Cole, M., 1960. Cerrado, caatinga and pantanal: Distribution and origin of the savanna vegetation of Brazil. Geogrl J. 126 (2): 186-179.

Dougherty, J. W. D., 1978. Salience and relativity in classification. Am. Ethnol. 5: $66-80$.

Gardner, P., 1976. Birds, words, and a requiem for the omniscient informant. Ibid. 3: 446-468.

Hueck, K., 1966. As florestas da América do Sul: Ecologia, composição e importância econômica. Editora da Universidade de Brasília, São Paulo.

Kempton, W., 1978. Category grading and taxonomic relations: A mug is a sort of cup. Am. Ethnol. 5: 44-65.

Lévi-Strauss, C., 1958. Anthropologie structurale. Plon, Paris.

Posey, D., 1978. Ethnoentomological survey of Amerind groups in lowland Latin America. Fla Ent. 61(4): 225-229.

Posey, D., 1979a. Kayapó controla inseto com uso adequado do ambiente. Revta Atual. indíg. 3(14): 47-58.

Posey, D., 1979b. Pyka-tô-ti: Kayapó mostra aldeia de origem. Ibid. 3(15): 50-57.

Posey, D., 1979c. Ethnoentomology of the Gorotire Kayapó of Central Brazil, PhD Dissertation, Department of Anthropology, University of Georgia, Athens.

Posey, D., 1980. Algunas observaciones etnoentomológicas sobre grupos amerindos en la América Latina. Amér. indig. 1(1): 105-120.

Posey, D., 1981a. Wasps, warriors and fearless men: Ethnoentomology of the Kayapó Indians of Central Brazil. J. Ethnobiol. 1(1).

Posey, D., 1981b. Folk ethology and apiculture of the Kayapó Indians of Brazil. J. Virgin Is. Archaeol. Soc. (in press).

Rosch, E., C. B. Mervis, W. Gray, D. Johnson \& P. Boyes-Braem, 1976. Basic objects in natural categories. Cognit. Psychol. 8: 382-439.

Steward, J. H. \& L. C. Faron, 1959. Native peoples of South America. McGraw-Hill, New York.

Stout, Mickey \& R. Thomson, 1971. Kayapó narrative. Int. J. Am. Linguistics 37(4): 250-256.

Stout, M. \& R. Thomsen, 1974. Fonêmica Txukahamei (Kayapó). Série Linguística 3: 153-176.

Verswijver, G., 1978. Enquête ethnographique chez les Kayapó-Mekrangoti: Contribution à l'étude de la dynamique des groupes locaux (scissions et regroupements). Unpublished Thesis, Ecole Pratique des Hautes-Etudes en Sciences Sociales, Paris.

Wagley, C., 1977. Welcome of tears: The Tapirapé Indians of Central Brazil. Oxford University Press, Oxford. 